\title{
Resenha: Textos e Termos por Lothar Hoffmann. Um convite para o estudo das linguagens técnico-científicas
}

\author{
Márcia Sipavicius Seide*
}

Finatto, M. J. B.; Zilıo, Leonardo (Orgs.). Textos e Termos por Lothar Hoffmann. Um convite para o estudo das linguagens técnico-científicas. Porto Alegre: Palotti, 2015, ISBN: 978-85-919265-0-3.

Três circunstâncias tornaram possível a publicação desta obra: a dedicação dos organizadores, tradutores, revisores e comentadores, o apoio financeiro da Fapergs e da Capes e a seção gratuita de direitos autorais por todos os autores, com inclusão de Hoffmann que a condicionou à distribuição pública e não comercial da tradução de sua obra no Brasil. Foram publicadas duas versões da obra: uma impressa, com tiragem limitada, e outra on-line disponível em dois sites: na guia "PUBLICAÇÕES" do site http://www.ufrgs.br/ppgletras/ e na guia "BIBLIOTECA" do site http:/ /www.ufrgs.br/termisul.

O livro reúne traduções da língua alemã para a língua portuguesa do Brasil uma seleção cuidadosa de dez textos do renomado pesquisador de linguagens especializadas alemão Lothar Hoffmann. Haver, para cada texto do pesquisador, outro texto que o comenta e, ao final da obra, fotos e informações sobre o investigador alemão, os tradutores, os revisores e os

\footnotetext{
* Prof ${ }^{a}$. Dra . em Língua Portuguesa e Filologia pela USP. Professora associada, docente do Programa de Pós-Graduação em Letras da Universidade Estadual do Oeste do Paraná, Campus de Cascavel e do Colegiado do Curso de Letras, do Campus de Marechal Cândido Rondon.
} 
SEIDE, M. S. - Resenha: Textos e Termos por Lothar Hoffman. Um convite para o estudo das linguagens técnico-científicas

comentadores são alguns diferenciais desta obra. Outro se relaciona com o processo de editoração. Os textos estão separados uns dos outros por uma folha preta antes e outra após cada seção. Comparando-as, percebem-se desenhos em cinza cuja imagem que jogam com a imagem da capa, conjunto de imagens que forma um texto imagético paralelo que pode dialogar com o texto escrito a depender da sensibilidade do leitor. Trata-se de imagens espaciais de satélites, estrelas e galáxias as quais podem sugerir, metaforicamente, a amplitude das ideias de Hoffmann e sua capacidade iluminadora.

$\mathrm{Na}$ apresentação, os organizadores justificam a necessidade de publicação dos textos de Hoffmann, informam como foram escolhidos e como o livro foi organizado. Explicam os organizadores que os trabalhos do pesquisador alemão são conhecidos e utilizados por um número restrito de pesquisadores no Brasil em virtude de, até então, não haver nenhuma tradução de seus textos à língua portuguesa. Esta informação confirma-se por uma busca rápida por artigos publicados on-line pela Revista TradTerm que citam Hoffmann. Essa busca revelou apenas quatro artigos publicados entre 2006 e 2012 por cinco autores, sendo que dois deles são os próprios organizadores da obra. Na parte dos comentários em que pesquisas utilizando suas propostas teóricas são mencionadas, também é possível perceber quão restrita tem sido a difusão de suas ideias: além de publicações cujo autor ou co-autor são os pesquisadores envolvidos com a publicação, apenas um trabalho mencionado não é oriundo deste círculo, indícios que apontam para a necessidade de difusão das ideias de Hoffmann no Brasil.

Dez foram os textos selecionados, traduzidos e comentados, citados aqui em ordem cronológica de publicação do original e, em parêntese, conforme ordenação realizada pelos organizadores: "Conceitos básicos da Linguística de Linguagens Especializadas", (texto 2) e "Do texto especializado ao gênero textual especializado", 1988 (texto 6); “Linguagens especializadas como sublinguagens" (texto 5); "Gêneros textuais especializados: uma 
SEIDE, M. S. - Resenha: Textos e Termos por Lothar Hoffman. Um convite para o estudo das linguagens técnico-científicas

concepção para a formação em línguas estrangeiras voltada para linguagens especializadas" (texto 8); “Métodos estatísticos para a pesquisa de linguagens especializadas" (texto 9), publicados em 1998; "O papel das linguagens especializadas desde meados do século XX”, 2000 (texto 1); “Linguagem especializada (texto 4) e "Pesquisa de linguagens especializadas" (texto 3 ).

Após leitura e releitura dos textos, na ordem proposta pelos organizadores, constata-se que foram seguidos critérios pedagógicos tendo em vista seu público alvo: leitores brasileiros sem conhecimento prévio do autor ou seus estudos. Assim, enquanto o texto 1 evidencia a importância dos estudos sobre as linguagens especializadas e traça um histórico da área na Europa, os textos 2 a 6 apresentam e definem os conceitos necessários para seu estudo, já os textos 7 a 10 informam, sintetizam e analisam pesquisas então já realizadas. Os dois últimos são os mais complexos, os que mais poderiam representar alguma dificuldade aos leitores, especialmente o texto 09 que trata da aplicação da Linguística Estatística ao estudo dos textos especializados.

No texto-comentário a respeito desse texto, Leonardo Zilio e Maria José Bocorny Finatto ponderam:

Nesse texto é preciso que o leitor linguísta tenha um pouco de paciênica e se esforçe para compreender alguns trechos "matemáticos" em que, por exemplo, são fornecidas fórmulas, algo pouco comum em textos de determinadas áreas da Linguística (...) Um linguista brasileiro que tenha já tido algum contato com a Linguística de Corpus (LC) poderá entender que esses procedimentos hoje são disponíveis em softwares específicos, que realizam e mostram esses cálculos. Para quem ainda não tenha proximidade com esses enfoques quantitativos e com a LC, recomendadmos consultar um número especial da revista Letras\&Letras sobre LC. Disponível em (...) (ZILIO \& FINATTO 2015: 179) 
SEIDE, M. S. - Resenha: Textos e Termos por Lothar Hoffman. Um convite para o estudo das linguagens técnico-científicas

Este trecho do comentário foi reproduzido por ilustrar a função pedagógica e contextualizadora apresentada por quase todos os textoscomentários da obra. Os comentadores se colocam na posição do leitor brasileiro, prevendo possíveis dificuldades. Além disto, relacionam as ideias de Hoffmann às áreas de pesquisa mais difundidas no Brasil e propõem leituras complementares, como o faz o bom professor dedicado à aprendizagem de seus alunos.

Outra função desses textos é a de tecer considerações sobre o processo tradutório. Essas considerações tiram da invisibilidade os tradutores e ressaltam a interface entre a Terminologia e da Tradução. Com relação ao texto 9 , há os seguintes comentários:

\begin{abstract}
Nessa seção, em que foram apresentados os modos de fazer esses cálculos, temos alguns elementos da tradução do texto que merecem ser apontados. Os cálculos muitas vezes não usavam uma notação estatística padronizada, de modo que os elementos presentes nos cálculos tiveram de ser traduzidos. Desse modo, por exemplo, SAQ (Summe der Abweichungsquadrate) virou, em português, SQD (Soma dos Quadrados do Desvio); $\mathrm{F}_{\mathrm{bi}}$ (beobachtete Häufigkeit der Variablen) traduzimos como $\mathrm{F}_{\mathrm{oi}}$ (frequência observada das variáveis) etc. (ZILIO \& FINATTO 2015: 181).
\end{abstract}

Comentários expressivos sobre a tradução foram feitos desde o primeiro texto-comentário: para explicar como foram encontradas as equivalências para um número significativo de palavras como o formativo "fach", é apresentada uma breve análise semântica e morfológica deste recurso na Língua Alemã e na língua de especialidade. A explicitação das particularidades da tradução do idioma teuto para o idioma nacional foi ressaltada neste ponto para justificar a necessidade de se fazer tais considerações:

Essas diferentes características da língua e outros elementos vinculados também à cultura linguística alemã são aspectos para os quais tentaremos chamar um pouco de atenção nos textos introdutórios de cada um dos artigos traduzidos para esta 
SEIDE, M. S. - Resenha: Textos e Termos por Lothar Hoffman. Um convite para o estudo das linguagens técnico-científicas

coletânea. Desse modo, além de ter contato com a belíssima obra de Lothar Hoffmann, o leitor pode também ter contato com alguns elementos linguísticos envolvidos no processo de compreensão e tradução dos textos que seguem (PINCKBRENNER \& ZILIO 2015: 20).

Cumpre informar que questões pedagógicas também faziam parte das cogitações do pesquisador alemão. Afirma ele no começo do texto 7 , cujo título é "Gêneros textuais especializados: uma concepção para a formação em línguas estrangeiras voltada pra linguagens especializadas":

(...) itens de um programa de melhorias logo foram incorporados pela Linguística de Linguagens Especializadas, e, até ó início dos anos 90 , surgiram vários trabalhos (...) apesar disso, nem sempre foi levado em conta que, para seus autores, além da Linguística Textual como filha da "virada comunicativa e pragmática", havia outra motivação muito forte para a transformação: as necessidades da formação em línguas estrangeiras voltada para linguagens especializadas, cujo objetivo declarado é a "competência linguística para agir na especialidade" (BUHLMANN e FEARNS, 1987, pp. 87-97) e competência comunicativa altamente desenvolvida em uma ou várias línguas estrangeiras (HOFFMANN 2015:128). (grifos nossos).

A leitura integral da obra permite avaliá-la em seu conjunto: a escolha acertada dos textos traduzidos, sua ordenação pedagógica e os comentários esclarecedores possibilitam o entendimento da Linguística de Linguagens Especializadas tal qual a propõe Hoffmann. Esta abordagem contempla todos os níveis de análise linguística, e não exclusivamente o léxico (como o faz a Terminologia proposta por Wüslerem 1974), relacionando-os. Pretende chegar à descrição das características dos gêneros textuais das linguagens especializadas, tendo em vista exigências múltiplas de seu uso, sejam as do objeto científico a ser estudo, as das situações comunicativas em foco ou das normas do fazer científico de cada área do conhecimento.

Hoffmann salienta as possibilidades de aplicação dos resultados das pesquisas tanto o ensino instrumental de línguas estrangeiras quanto o de 
SEIDE, M. S. - Resenha: Textos e Termos por Lothar Hoffman. Um convite para o estudo das linguagens técnico-científicas

língua materna. Defende que ambas visam o letramento acadêmico na área em que o aluno é especialista, para além, é claro, de uma melhor compreensão de como funcionam as linguagens especializadas. Comprova-se o que afirma Valdir do Nascimento Flores ao apresentar o livro aos leitores na aba ou orelha do livro:

Este livro apresenta uma excelente seleção de textos que refletem o pensamento do renomado linguista Lothar Hoffmann, cuja obra ficou por muito tempo às margens da contemplação brasileira, principalmente por estar escrita em alemão. As traduções aqui apresentadas fazem esta ponte, ajudando o leitor brasileiro a desvendar as ideias desse autor. 